\title{
LAPAROSCOPIC CHOLECYSTECTOMY; IS CONVERSION REALLY A COMPLICATION- A PROSPECTIVE STUDY TO EVALUATE COMPLICATIONS AND CONVERSION RATES
}

\author{
Santosh Kumar Sonker1, Rohit Jain², Pratik Barle ${ }^{3}$ \\ ${ }_{1}^{1}$ Associate Professor, Department of Surgery, Dr. Bhimrao Ambedkar Memorial Hospital, Raipur, Chhattisgarh, India. \\ ${ }^{2}$ Assistant Professor, Department of Surgery, Dr. Bhimrao Ambedkar Memorial Hospital, Raipur, Chhattisgarh, India. \\ ${ }^{3}$ Senior Resident, Department of Emergency and Trauma, Dr. Bhimrao Ambedkar Memorial Hospital, Raipur, Chhattisgarh, India. \\ ABSTRACT

\section{BACKGROUND} \\ In this era of advanced surgical approaches, Laparoscopic Cholecystectomy is the procedure of choice for gall bladder diseases. But \\ fear of conversion to open cholecystectomy is really a night mare among surgeons and patients. Good counselling and better \\ predictability can avert the misconception of conversion as a complication of it. This study was conducted with an aim to evaluate \\ complications as well as conversion rates in normal and high risks patients.
}

\section{MATERIALS AND METHODS}

The study included all adult subjects who have definite clinical, biochemical and radiological indications for laparoscopic cholecystectomy. After clearance from the ethical committee, we also included those patients in whom laparoscopic cholecystectomy was previously not frequently performed like acute cholecystitis, chronic cholecystitis, history of previous upper abdominal surgeries, and in obese patients with BMI>30. Definitely benefits outweigh risks in these patients. Statistical analysis was done by using chi square test, Fisher's exact test with the help of SPSS version 20.

\section{RESULTS}

We have observed that out of 67 subjects, $n=22,32.8 \%$ were between $31-40$ years of age, $n=43,64.1 \%$ were females and $n=24$, $35.8 \%$ were males. Commonest complaint is abdominal pain present in $n=43,64.2 \%$. Cholelithiasis was the most common indication present in $n=52,82 \%$ patients. Out of 67 patients, $n=6,8.9 \%$ had history of upper abdominal surgeries, acute cholecystitis present in $\mathrm{n}=9,13.4 \%$, chronic cholecystitis in $\mathrm{n}=3,4.4 \%$ and $\mathrm{n}=2,2.9 \%$ had $\mathrm{BMI}>30 \mathrm{~kg} / \mathrm{m}^{2}$. Total conversion rate was $\mathrm{n}=8,11.9 \%$ which was slightly high as we have included high risk patients also. But still we have avoided conversion in total $\mathrm{n}=4,66.6 \%$ with upper abdominal surgeries, $\mathrm{n}=2,66.6 \%$ patients with chronic cholecystitis, $\mathrm{n}=4,100 \%$ in acute cholecystitis of pain duration $<72$ hours and $n=2,100 \%$ obese patients. Although $p$-value calculated by chi square test was found to be 0.3126 [>0.05].

\section{CONCLUSION}

Definitely, conversion should never be considered as a complication of laparoscopic cholecystectomy and there is no question that laparoscopic cholecystectomy is the gold standard for gallbladder diseases.

\section{KEY WORDS}

Laparoscopic Cholecystectomy [LC], Acute Cholecystitis [AC], Chronic Cholecystitis [CC].

HOW TO CITE THIS ARTICLE: Sonker SK, Jain R, Barle P. Laparoscopic cholecystectomy; is conversion really a complication- a prospective study to evaluate complications and conversion rates. J. Evolution Med. Dent. Sci. 2019;8(03):217-222, DOI: $10.14260 /$ jemds/2019/47

\section{BACKGROUND}

Laparoscopic Cholecystectomy now became a boon to surgeons for treating gall bladder diseases; its advantages over open cholecystectomy are well known to surgeons. Many studies are already being done evaluating the complications especially conversion rates and predicting the risk factors. But sometimes due to all these researches, day by day conversion is becoming a night mare among surgeons and in setups like medical colleges, it became a back ground for rumours and raised a question mark on competency and skills of surgeons who are operating and having higher conversion rates comparable to others.

'Financial or Other Competing Interest': None.

Submission 13-12-2018, Peer Review 07-01-2019,

Acceptance 14-01-2019, Published 21-01-2019.

Corresponding Author:

Dr. Rohit Jain

D-200, RMS Colony, Tagore Nagar,

Raipur-492001, Chhattisgarh, India.

E-mail: rohitjainsx@gmail.com

DOI: $10.14260 /$ jemds $/ 2019 / 47$

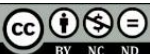

Also, sometimes in government setups it leads to a negative counselling of patients who had some underlying high-risk factors for conversion. Still conversion rate in laparoscopic cholecystectomy is $2.4-14 \% .^{1}$ Definitely the rate of conversion to open surgery and the complication rate are low in experienced hands. All surgeons should keep a low threshold for conversion to open surgery and it should be taken as a step in the interest of the patient rather than be looked upon as an insult to the surgeon. ${ }^{2}$ If not unduly delayed, conversion carries similar risks to open cholecystectomy whereas 'enforced' conversion usually following severe iatrogenic injury or bleeding is associated with higher morbidity and mortality. ${ }^{3}$ The aim of our study is to evaluate complication as well as conversion rates in normal and high risks patients. Conversion should not be considered a technical failure but rather accepted as a better surgical practice by the patient and surgeon when indicated.

\section{MATERIALS AND METHODS}

It is a prospective observational study done between January 2016 to September 2017 on those subjects who were 
admitted in Unit-4, Department of Surgery, Dr. Bhimrao Ambedkar Memorial Hospital, Raipur, Chhattisgarh and are planned for elective laparoscopic cholecystectomy. During this period, 67 patients were admitted in Unit-4 and hence enrolled for our study. After clearance from the ethical committee, a positive counselling with informed and written consent was done explaining the risks of laparoscopic cholecystectomy and possibilities of conversion. The sample size estimation was also done at conveniences.

\section{Inclusion Criteria}

1. Age $>18$ years

2. Clinical, biochemical, radiological background present for cholelithiasis

- Acute Cholecystitis of pain duration $<72$ hours.

- Acute Cholecystitis of pain duration $>72$ hours.

- Chronic Cholecystitis.

\section{Exclusion Criteria}

Patients with CBD stones, Jaundice or abnormal LFT, known cases of CA Gall Bladder, Peritonitis, Biliary enteric fistula and portal hypertension etc. were excluded from study.

Laparoscopic Cholecystectomy was performed by consultants with assistance by residents using the conventional 4 port method under general anaesthesia. Supervision and intervention were done by Senior Consultants in patients who possessed high risks for conversion. Final data analysis was done by using Chi square test, Fisher's exact test with help of SPSS version 20.
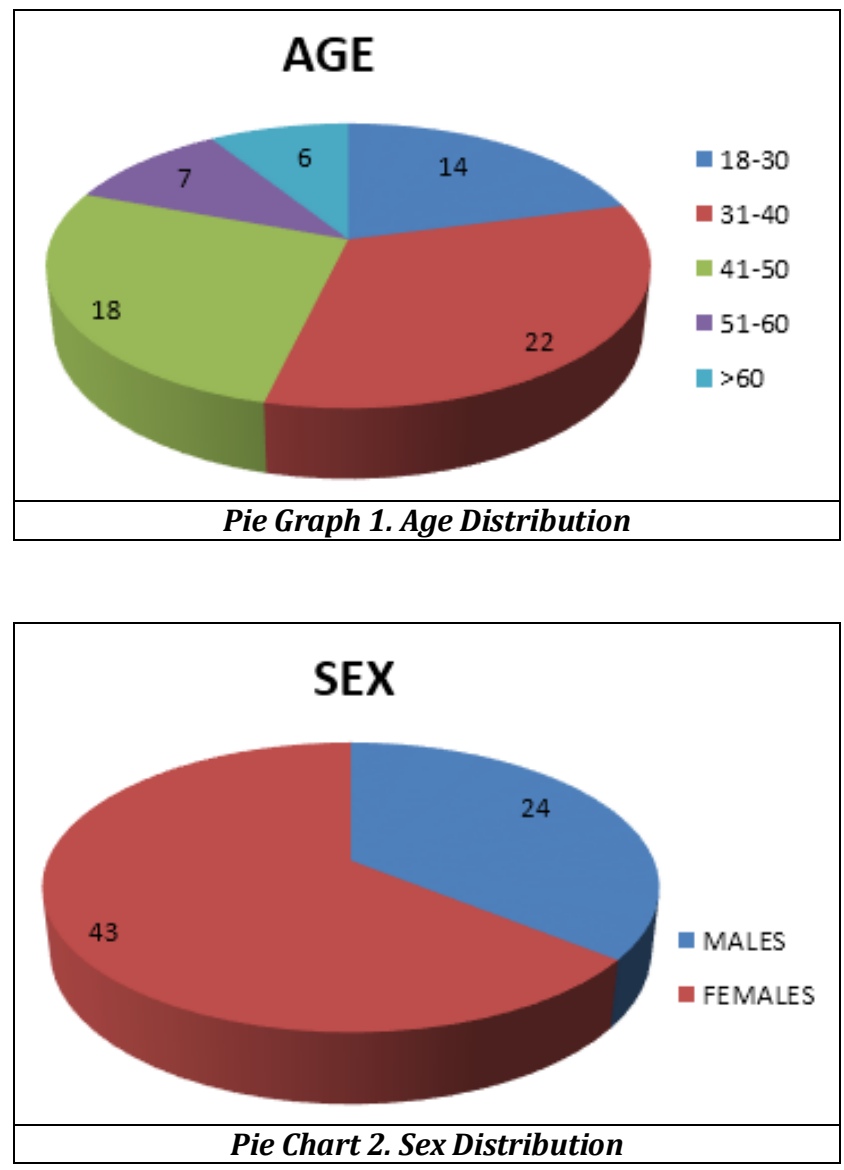

\section{CONVERSION RATES}

0

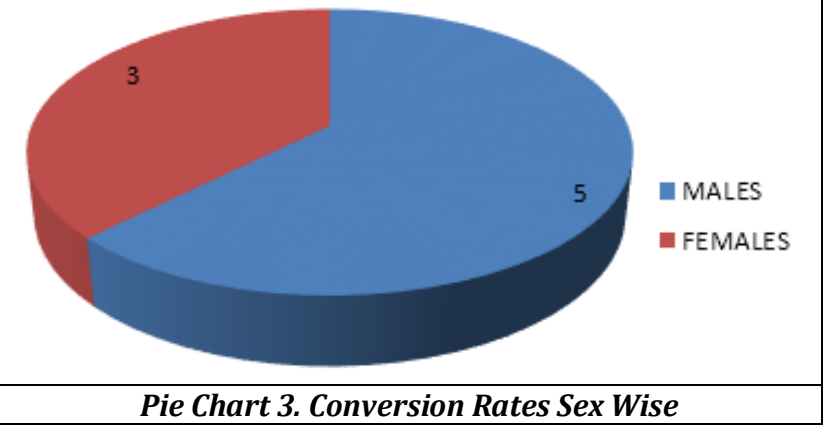

\begin{tabular}{|c|c|c|}
\hline Complications & Number & Percentage \\
\hline Wound Infection & 8 & $11.9 \%$ \\
\hline Pulmonary Complications & 3 & $4.5 \%$ \\
\hline CBD Injury & 1 & $1.49 \%$ \\
\hline Excessive Haemorrhage & 1 & $1.49 \%$ \\
\hline Bile Leak & 2 & $3 \%$ \\
\hline Total & $\mathbf{1 5}$ & $\mathbf{2 2 . 3 \%}$ \\
\hline Table 1. Complications Observed \\
\hline
\end{tabular}

\begin{tabular}{|c|c|c|c|c|c|c|}
\hline $\begin{array}{c}\text { Risk } \\
\text { Factors }\end{array}$ & $\begin{array}{c}\text { No. Of } \\
\text { Patients } \\
\text { Having } \\
\text { Risk } \\
\text { Factors }\end{array}$ & $\begin{array}{r}\mathbf{N} \\
\mathrm{Pa} \\
\text { Con } \\
{[\mathrm{Gr}}\end{array}$ & $\begin{array}{l}\text { o. of } \\
\text { ients } \\
\text { verted } \\
\text { up-A] }\end{array}$ & $\begin{array}{r}1 \\
\text { Pat } \\
\mathrm{V} \\
\text { Con } \\
\text { At } \\
{[\mathrm{Gr}}\end{array}$ & $\begin{array}{l}\text { lo. of } \\
\text { ients in } \\
\text { lhom } \\
\text { version } \\
\text { oided } \\
\text { oup-B] } \\
\end{array}$ & $\begin{array}{l}\text { p-Value } \\
\text { Calculated } \\
\text { by Chi } \\
\text { Square } \\
\text { Test }\end{array}$ \\
\hline $\begin{array}{c}\text { Upper } \\
\text { Abdominal } \\
\text { Surgeries }\end{array}$ & 6 & 2 & $33.3 \%$ & 4 & $66.6 \%$ & \multirow{5}{*}{$\begin{array}{l}0.001 \\
0.025 \\
0.003 \\
0.016 \\
0.005\end{array}$} \\
\hline $\mathrm{AC}<72$ Hours & 4 & nil & nil & 4 & $100 \%$ & \\
\hline$A C>72$ Hours & 5 & 3 & $60 \%$ & 2 & $40 \%$ & \\
\hline $\mathrm{CC}$ & 3 & 1 & $33.3 \%$ & 2 & $66.6 \%$ & \\
\hline $\begin{array}{l}\text { Obesity, } \\
\text { BMI>30 }\end{array}$ & 2 & nil & nil & 2 & $100 \%$ & \\
\hline
\end{tabular}

\section{RESULTS}

In our study on 67 subjects who underwent Laparoscopic cholecystectomy, we found that maximum number of patients belong to age group 31-40 years $n=22,32.8 \%$ [Pie Graph 1]. Female cases predominant over male cases and male: female ratio was 1:1.79 [Pie Graph. 2]. Most of the patients presented with complaint of abdominal pain $n=43,64.2 \%$. Vomiting was there in $n=15,22.3 \%$ and $n=18,26.8 \%$ had history of fever. Cholelithiasis was present in $n=55,82 \%$ and was the commonest diagnosis. We have intentionally included patients of Acute Cholecystitis $n=9,13.4 \%$ and Chronic Cholecystitis $n=3,4.47 \%$ as these patients were prone for conversion.) Since the duration of the study was less. The patients were selected by convenience.

Complications were low in our setup, $n=8,11.9 \%$ patients had postoperative wound infection. Only $n=3,4.5 \%$ patients had minor pulmonary complications. Only $n=2,3 \%$ had postoperative bile leak [Observation table-1]. Special emphasis was given on conversion rates, detailed evaluation for underlying risk factor and later on need for conversion was done. Out of 67 patients in our study $n=20,29.8 \%$ had high risk factors for conversion [Observation table-2]. $\mathrm{N}=7$, $10.4 \%$ had age $>60$ years. History of previous upper abdominal surgery was present in $n=6,8.9 \%$. Acute cholecystitis with pain duration $<72$ hours was present in 
$\mathrm{n}=4,5.9 \%$ and pain duration $>72$ hours was there in $\mathrm{n}=5$, 7.4\%. Chronic Cholecystitis was present in $n=3,4.4 \%$. Only $\mathrm{n}=2, \quad 2.9 \%$ were obese with $\mathrm{BMI}>30 \mathrm{~kg} / \mathrm{m}^{2}$. Overall conversion rate in our study was $11.9 \% \mathrm{n}=8$. We found that there was a male predominance for conversion and $n=5$, $7.46 \%$ males are subjected to open cholecystectomy whereas only $n=3,4.47 \%$ females had conversion. When risk factors were considered individually, we were successful in avoiding conversions in $\mathrm{n}=4,66.6 \%$ patients who had previous abdominal surgeries. All $100 \%$ patients were successfully operated by laparoscopic cholecystectomy who had acute cholecystitis $<72$ hours pain duration and similarly no conversion was required in obese patients. We have also prevented $n=2,40 \%$ of patients of acute cholecystitis with pain duration $>72$ hours and $n=2,66.6 \%$ of patients with chronic cholecystitis from conversion. [Observation Table-2]. When $p$-value $\leq 0.05$ was calculated by using Chi square test it came out to be 0.3126 [ $>0.05]$. $\mathrm{N}=1,1.49 \%$ had CBD injury and $n=1,1.49 \%$ had severe haemorrhage for which timely conversion was done although they do not have any predisposing factor for conversion. P-value $>0.05$ was considered significant.

\section{Statistical Analysis}

Statistical analysis was performed using the SPSS 16.0 statistical software package (SPSS Inc., Chicago, IL, USA). Data analysed using $\chi 2$ for qualitative with One-Way ANOVA used for quantitative variables.

\section{DISCUSSION}

Laparoscopic Cholecystectomy is one of the frequently performed surgeries and it has almost replaced open cholecystectomy due to its definite advantages specially postoperative morbidity, but the risk of intraoperative injury during laparoscopic cholecystectomy is higher than in open cholecystectomy.4,5 The true complications of laparoscopic cholecystectomy are haemorrhage, gallbladder perforation, bile leakage, bile duct injury and visceral injury. ${ }^{6}$ But the incidence of these injuries had decreased with the passage of time due to increased experience of the surgeons, popularity of the procedure and introduction of new instruments. ${ }^{7}$ Even conversion required in certain situations could help in preventing complications. ${ }^{6}$

In our study, out of 67 patients, maximum number of patients $n=22,32.83 \%$ were in the age group between $31-40$ years, $n=7,10.44 \%$ between $51-60$ years and $n=6,8.9 \%$ were $>60$ years of age [Pie Graph- 2]. Gall bladder diseases are more commoner in younger age. Female cases predominant over male with ratio of 1.79:1. Fat, female and forty is a predisposing factor. Similar incidence of female predominance was found in the study of Mallik et al. ${ }^{8}$ This may be due to the fact that during pregnancy and child birth there is biliary stasis and weight gain with hypercholesterolemia and formation of gall stones. Cholelithiasis being the commonest indication present in $\mathrm{n}=55,82 \%$ for which laparoscopic cholecystectomy was performed.

Acute and Chronic Cholecystitis are initially relative contraindications for laparoscopic cholecystectomy and it always remained a controversial issue to proceed for the procedure in these patients as there are difficulties to reach gall bladder in these patients and are at high risks for conversions. We have included $n=9,13.4 \%$ patients of acute cholecystitis and $n=3,4.4 \%$ patients of chronic cholecystitis. Maitra et al $^{9}$ have also included $69.2 \%$ patients of chronic cholecystitis and $18.6 \%$ cases of acute cholecystitis. Biswas et al 10 have done a prospective study on patients of acute cholecystitis dividing them into two groups according to duration of symptoms. Several other randomized and nonrandomized studies are also conducted documenting the feasibility and safety of laparoscopic cholecystectomy in acute cholecystitis. ${ }^{11-15}$ In contrast Mallik et al ${ }^{7}$ have placed acute cholecystitis in their exclusion criteria. Gokaken et al ${ }^{16}$ have also accepted existence of acute cholecystitis as a criterion of exclusion. Laparoscopic cholecystectomy has virtually replaced conventional open cholecystectomy as the gold standard for symptomatic cholelithiasis and chronic cholecystitis. ${ }^{17,18}$

The actual intraoperative complications of laparoscopic cholecystectomy are intra-abdominal bile leak due to common bile duct injury, perforation of gall bladder and haemorrhage. In our study, we encountered one patient $(1.49 \%)$ who had uncontrolled haemorrhage requiring conversion and 1 patient (1.49\%) had common bile duct injury requiring conversion. This was quite low in comparison to study done by Maitra et al $^{9}$ where bleeding and common bile duct injury was $11 \%$ and $4 \%$ respectively.

In our study port site infection was noticed in $n=8,11.9 \%$ cases [Observation table-1]. In other study by Maitra et al, ${ }^{9}$ surgical site infection was seen in $5.2 \%$ cases. Significant reduction in postoperative infection is one of the main benefits of minimally invasive surgery as the rate of surgical site infection is $2 \%$ and $8 \%$ in open surgery ${ }^{19}$. In another study it was reported as $1.4 \%$ in laparoscopic surgeries versus $14.8 \%$ in open cases. ${ }^{20}$ Minor pulmonary complications were present in $n=3,4.5 \%$ of cases. It was due to general anaesthesia and underlying pulmonary diseases in these patients.

A thorough evaluation was done on conversion rates in our study which was actually $\mathrm{n}=8 \quad 11.9 \%$. The overall conversion rate is $2.6 \%$ to $14 \%$ as described in literature. ${ }^{1}$ Actually we want to emphasize on the point that conversion should not be considered as a complication but actually it is a step to prevent untoward events that may happen to patients, if attempts for a difficult laparoscopic cholecystectomy is being continued.

Definitely surgical decision making plays the most critical role in cases of difficult gall bladder and may prove to be the most challenging aspect of the case. ${ }^{21}$ The surgeon should not be afraid to call a colleague for help as this is in fact an evidence of good judgement. However, simply converting to an open operation in difficult situations is often not adequate as a difficult laparoscopic cholecystectomy remains a difficult open cholecystectomy. 22 Keeping in mind the above facts we have intentionally operated patients with high risk factors under supervision of senior consultants who are competent in open cholecystectomy too. By this step were successfully able to avoid conversion in significant number of patients who were at high risks of conversions and even those who were opened we have performed a successful cholecystectomy without complications.

But definitely for doing all these things risk factors should be kept in mind and a thorough analysis was done in our study. We found that out of $n=20,29.6 \%$ who had underlying 
risk factors we have avoided conversion in $n=14,20.8 \%$ of patients. When question for statistical analysis came, we applied a chi square test and found that p-value was 0.3126 [ $>0.05]$ which was not significant but we were actually not worried so much about this theoretical value as we had practically observed the patients $[n=14,20.8 \%]$ who were really benefited from laparoscopic cholecystectomy instead of open surgery with underlying risk factors.

In our study $n=6,8.9 \%$ were more than 60 years of age. Out of 8 [11.9\%] patients which required conversion $n=3$, $4.4 \%$ of them were more than 60 years of age which is significant. Wiebke et al, Kannansa et al, Simopoulous et al,23,24,25 significantly correlated age with an increased conversion rate. Fried GM et $\mathrm{al}^{26}$ opined that it is difficult to delineate the anatomy in elderly patient with long history of gall bladder diseases. In contrary to these studies, Nikhil et al 27 found that patients with age $<45$ years were associated with slightly more incidence of increasing difficulty. Also, Mallik et $\mathrm{al}^{8}$ found that maximum converted patients were in the age group of $26-30$ years i.e. 5 patients $(17.86 \%)$. The conversion rates and complications associated with laparoscopic cholecystectomy is affected by factors such as history of previous abdominal surgery, recurrent attacks of cholecystitis, acute cholecystitis, advanced age of the patient, obesity or male gender. 25,28,29

In our study also, conversion was more common in males $7.46 \%$ versus $4.47 \%$ in females [Pie Graph -3]. Awan et al ${ }^{30}$ have also found that conversion rate was higher among males $(15.1 \%)$ as compared to females $(3.4 \%)$. Fried GM et $\mathrm{al}^{26}$ explained that higher risk associated with male patients is due to increased likelihood of acute cholecystitis, older age and increased gall bladder wall thickness. In contrary Nikhil et $\mathrm{al}^{27}$ do not found male predominance. An explanation of higher rates in males might be that men are more likely to delay seeking help and thereby present themselves with a more severe disease when they are operated. ${ }^{31,32}$

Morbid obesity is also associated with increased risk of conversion. ${ }^{33}$ Hutchinson et $\mathrm{al}^{34}$ reported two times increase in conversion rate when BMI is more than $27.2 \mathrm{~kg} / \mathrm{m}^{2}$. Mohanty et $\mathrm{al}^{35}$ have also found obesity as a significant risk factor for conversion. Awan NA et al ${ }^{30}$ have also founded that BMI more than 30 have increased rate of conversion. In our study $\mathrm{n}=2,2.9 \%$ patients were obese with BMI more than 30 but we have succeeded in preventing open cholecystectomy in these 2 patients, but surgery was done under supervision of senior surgeons. Similar to our study Jethwani et al $^{2}$ stated that none of their obese patient has to be converted to open. Simpoulous et al25 declared that laparoscopic cholecystectomy is effective and safe in patient with morbid obesity.

A thorough literature review over the past decade shows that early laparoscopic cholecystectomy for acute cholecystitis is extremely safe. 15,36,37 Even Tokyo ${ }^{38}$ guidelines also supported this. Biswas et $\mathrm{al}^{10}$ have divided patients in two groups with acute cholecystitis with more than 72 hours duration and less than 72 hours duration and found that there was no conversion and complications in group 2 whereas 4 patients require conversion and 2 develop postoperative complications in group 1 . They support laparoscopic intervention within 72 hours after onset of symptoms for acute cholecystitis. This is due to the fact that oedema planes magnify the structures and facilitates dissection. Jitendra Singh Yadav et al,39 Fried et $\mathrm{al}^{26}$ also considered acute cholecystitis to be a risk factor for conversion. In our study also $n=4,5.9 \%$ patients had acute cholecystitis of less than 72 hours, we have prevented conversion in all of them, but in 3 out of 5 patients with acute cholecystitis more than 72 hours duration were converted to open surgery that is $40 \%$ of such patient required conversion. Volkan Genc et al ${ }^{6}$ have done a retrospective analysis of 5164 consecutive laparoscopic operation, they found that conversion rates in cases with acute cholecystitis were reported in the literature to reach up to $27.7 \%$. Josephine Philip Rothman et al ${ }^{40}$ have also done a meta-analysis of observational studies and concluded that acute cholecystitis was a risk factor of conversion. The major reason for conversion to be the failure of anatomical identification of calot's triangle because of severe inflammation caused either by acute cholecystitis or by dense adhesions caused by recurrent attacks of cholecystitis.

We have also included 3 patients of chronic cholecystitis and only 1 required conversion i.e. we have prevented 2 patients from conversion. Nachanani et $\mathrm{al}^{33}$ have also interpreted that attacks of cholecystitis $>6$ months have more chances of difficult laparoscopic cholecystectomy and conversion, most probably due to adhesions at Calot's triangle and gall bladder fossa. Nikhil et $\mathrm{al}^{27}$ have also concluded the same. Sanabria et $\mathrm{al}^{41}$ have also examined risk factor in 628 patients and patients with multiple attacks $>10$ of biliary colic with documented history of acute cholecystitis were more likely for conversion.

In our study $n=6,8.9 \%$ patients have previous upper abdominal surgeries and out of them 2 required conversion. We had avoided conversion in 4 [66.6\%] patients. Awan NA et $\mathrm{al}^{30}$ found the rate is $17.4 \%$ which is very high in patients with upper abdominal surgeries due to adhesions. Prieto DE et $\mathrm{al}^{42}$ found in a study that patients who underwent previous abdominal surgeries were found to have increased difficulty during laparoscopic cholecystectomy in terms of adhesions in the upper abdomen. The conversion rate was more in upper abdominal surgeries [20\%] compared to lower abdomen [4.7\%]. But according to them with increased experience surgeons would overcome this difficulty. Nevertheless, laparoscopic cholecystectomy seems to be the treatment of choice for acute and chronic cholecystitis. ${ }^{43}$

\section{CONCLUSION}

The primary goal of laparoscopic cholecystectomy is "safety first, total cholecystectomy second". While the majority of laparoscopic cholecystectomies will be safely performed, the surgeon should always keep the culture of safety at forefront without any hesitation. Conversion is neither a complication nor a question mark on the competency of a surgeon, but timely decision reveals the sound judgement of the surgeon in view of safety of the patient. Conversion should never be a night mare for surgeons.

\section{REFERENCES}

[1] Ibrahim S, Hean TK, Ho LS, et al. Risk factors for conversion to open surgery in patients undergoing laparoscopic cholecystectomy. World J Surg 2006;30(9):1698-704. 
[2] Jethwani U, Singh G, Mohil RS, et al. Prediction of difficulty and conversion in laparoscopic cholecystectomy. OA Minimally Invasive Surgery 2013;1(1):2.

[3] Tang B, Cuschieri A. Conversions during laparoscopic cholecystectomy: risk factors and effects on patient outcome. J Gastrointest Surg 2006;10(7):1081-91.

[4] Hobbs MS, Mai Q, Knuimam MW, et al. Surgeon experience and trends in intraoperative complications in laparoscopic cholecystectomy. $\mathrm{Br} J$ Surg 2006;93(7):844-53.

[5] Hasl DM, Ruiz OR, Baumert J, et al. A prospective study of bile leaks after laparoscopic cholecystectomy. Surg Endosc 2001;15(11):1299-300.

[6] Genc V, Sulaimanov M, Cipe G, et al. What necessitates the conversion to open cholecystectomy? A retrospective analysis of 5164 consecutive laparoscopic operations. Clinics (Sao Paulo) 2011;66(3):417-20.

[7] Shamiyeh A, Wayand W. Laparoscopic cholecystectomy: early and late complication and their treatment. Langenbecks Arch Surg 2004;389(3):16471.

[8] Mallik NR, Bhattacharyya S, Saha AK, et al. A study on the conversion rate of laparoscopic cholecystectomy to open cholecystectomy and its causes with special reference to rural population. IOSR-JDMS 2018;17(4):51-7.

[9] Maitra TK, Ullah ME, Faruquzzaman, et al. Operative and postoperative complications of laparoscopic cholecystectomy: experience from a tertiary care hospital of Bangladesh. Bangladesh Crit Care J March 2017;5(1):11-6.

[10] Biswas SK, Saha JC, Rahman MM, et al. Laparoscopic cholecystectomy in acute calculus cholecystitisexperience at district level hospital. Faridpur Med Coll J 2010;5(1):3-6.

[11] Garber SM, Korman J, Cosgrove JM, et al. Early laparoscopic cholecystectomy for acute cholecystitis. Surg Endosc 1997;11(4):347-50.

[12] Stevens KA, Chi A, Lucas LC, et al. Immediate laparoscopic cholecystectomy for acute cholecystitis: no need to wait. Am J Surg 2006;192(6):756-61.

[13] Lo CM, Liu CL, Fan ST, et al. Prospective randomized study of early versus delayed laparoscopic cholecystectomy for acute cholecystitis. Ann Surg 1998;227(4):461-7.

[14] Johansson M, Thune A, Blomqvist A, et al. Management of acute cholecystitis in laparoscopic era: results of a prospective, randomized clinical trial. J Gastrointest Surg 2003;7(5):642-5.

[15] Papi C, Catarci M, D’Ambrosio L, et al. Timing of cholecystectomy for acute cholecystitis: a metaanalysis. Am J Gastroenterol 2004;99(1):147-55.

[16] Gokakin AK, Atabey M, Krakus BC, et al. Conversion to open surgery in the era of laparoscopic cholecystectomy: rates and reasons. Cumhuriyet Med Journal 2012;34:314-8.

[17] Cawich So, Mitchell DI, Newnham MS, et al. A comparison of open and laparoscopic cholecystectomy done by a surgeon in training. West Indian Med J 2006;55(2):103-9.
[18] Al-Salamah SM. Outcome of laparoscopic cholecystectomy in acute cholecystitis. J Coll Physicians Surg Pak 2005;15(7):400-3.

[19] Boni L, Benevento A, Rovera F, et al. Infective complications in laparoscopic surgery. Surg Infect (Larchmet) 2006;7 Suppl 2:109-11.

[20] Chuang SC, Lee KT, Chang WT, et al. Risk factors for wound infection after cholecystectomy. J Formos Med Assoc 2004;103(8):607-12.

[21] Pucci MJ, Brunt LM, Deziel DJ. Safety first, total cholecystectomy second. J Am Coll Surg 2016;223(3):543-4.

[22] Santos BF, Brunt LM, Pucci MJ. The difficult gallbladder: a safe approach to a dangerous problem. Journal of Laparoendoscopic and Advanced Surgical Techniques 2017;27(6):571-8.

[23] Wiebke EA, Pruitt AL, Howard TJ, et al. Conversion of laparoscopic to open cholecystectomy. An analysis of risk factors. Surg Endosc 1996;10(7):742-5.

[24] Kanaan SA, Murayama KM, Merriam LT, et al. Risk factors for conversion of laparoscopic to open cholecystectomy. J Surg Res 2002;106(1):20-4.

[25] Simopoulos C, Botaitis S, Polychronidis A, et al. Risk factors for conversion of laparoscopic cholecystectomy to open cholecystectomy. Surg Endosc 2005;19(7):905-9.

[26] Fried GM, Barkun JS, Sigman HH, et al. Factors determining conversion to laparotomy in patients undergoing laparoscopic cholecystectomy. Am J Surg 1994;167(1):35-9, discussion 39-41.

[27] Khandelwal N, Salim M, Gandhi A. Predicting difficult laparoscopic cholecystectomy based on clinico radiological parameters. Scholars Journal of Applied Medical Sciences (SJAMS) 2017;5(4B):1343-7.

[28] Ercan M, Bostanci EB, Ulas M, et al. Effects of previous abdominal surgery incision type on complications and conversion rate in laparoscopic cholecystectomy. Surg Laparosc Endosc Percutan Tech 2009;19(5):373-8.

[29] Botaitis S, Polychronidis A, Pitiakoudis M, et al. Does gender affect laparoscopic cholecystectomy? Surg Laparosc Endosc Percutan Tech 2008;18(2):157-61.

[30] Awan NA, Hamid F, Mir IN, et al. Factors resulting in conversion of laparoscopic cholecystectomy to open cholecystectomy-institution based study. International Surgery Journal 2018;5(1):132-7.

[31] Richards HM, Reid ME, Watt GC. Socioeconomic variations in responses to chest pain: qualitative study. BMJ 2002;324(7349):1308.

[32] White AK, Johnson M. Men making sense of their chest pain - niggles, doubts and denials. J Clin Nurs 2000;9(4):534-41.

[33] Nachnani J, Supe A. Pre-operative prediction of difficult laparoscopic cholecystectomy using clinical and ultrasonographic parameters. Indian Journal of Gastroenterology 2005;24(1):16-8.

[34] Hutchinson CH, Traverso LW, Lee FT. Laparoscopic cholecystectomy. Do pre-operative factors predict the need to convert to open? Surg Endosc 1994;8(8):8758, discussion 879-80. 
[35] Mohanty SK, Mohanty R. Pre-operative prediction of difficult laparoscopic cholecystectomy using clinical and ultrasonographic parameters. Annals of International Medical and Dental Research 2017;3(4):43-8.

[36] Al-Mulhim AA. Timing of early laparoscopic cholecystectomy for acute cholecystectomy. Journal of the Society of Laparoendoscopic Surgeons 2008;12(3):282-7.

[37] Sinha R, Sharma N. Acute cholecystitis and laparoscopic cholecystectomy. Journal of the Society of Laparoendoscopic Surgeons 2002;6(1):65-8.

[38] Yamashita Y, Takada T, Kawarada Y, et al. Surgical treatment of patients with acute cholecystitis: Tokyo Guidelines. J Hepatobiliary Pancreat Surg 2007;14(1):91-7.

[39] Yadav JS, Gupta A, Shrivastava P, et al. Study of correlation of preoperative clinical, laboratory, sonological and peroperative findings in gall stone disease. Sch J App Med Sci 2014;2(3B):966-70.
[40] Rothman JP, Burcharth J, Pommergaard HC, et al. Preoperative risk factors for conversion of laparoscopic cholecystectomy to open surgery - a systematic review and meta-analysis of observational studies. Digestive Surgery 2016;33(5):414-23.

[41] Sanabria JR, Gallinger S, Croxford R, et al. Risk factors in elective laparoscopic cholecystectomy for conversion to open cholecystectomy. J Am Coll Surg 1994;179(6):696-704.

[42] Prieto-Diaz-Chavez E, Median-Chavez JL, GonzalezOjeda A, et al. Direct trocar insertion without pneumoperitoneum and the veress needle in laparoscopic cholecystectomy: a comparative study. Acta Chir Belg 2006;106(5):541-4.

[43] Zacks SL, Sandler RS, Rutledge R, et al. A populationbased cohort study comparing laparoscopic cholecystectomy and open cholecystectomy. Am J Gastroenterology 2002;97(2):334-40. 